\title{
МАРКЕТИНГОВЫЙ АНАЛИЗ СОСТОЯНИЯ И ТЕНДЕНЦИЙ РАЗВИТИЯ НАЦИОНАЛЬНОЙ ИНДУСТРИИ ТУРИЗМА
}

\section{(c) 2019 Сагидуллаева Мадина Сейдуллаевна}

соискатель, старший преподаватель кафедры «Бухучет-1»

Ростовский государственный экономический университет «РИНХ», Россия, Ростов-на-Дону Дагестанский государственный университет народного хозяйства, Россия, Р. Дагестан, Махачкала

В статье представлены результаты маркетингового анализа состояния и тенденций развития национальной индустрии туризма, подтверждающие необходимость борьбы за внутреннего туриста в нестабильных условиях туристского рынка, что требует реорганизации системы маркетингового управления отраслью, которая должна обладать свойством «управляемой адаптации» к внешним изменениям.

Ключевые слова: индустрия туризма, туристский маркетинг, маркетинговый анализ, внутренний, въездной и выездной туризм, туристская инфраструктура, адаптивное управление маркетингом.

Повышенная восприимчивость туристов к изменению социально-экономических и политических факторов окружающей среды является важнейшей особенностью туристского маркетинга [1], что предопределяет необходимость регулярно отслеживать состояние и тенденции развития этой среды, и соответственно выявлять флуктуации потребительского поведения целевой аудитории туристов в сравнительном контексте.
В этой связи, используя рейтинги Всемирного экономического форума (ВЭФ) и Всемирного совета по туризму и путешествиям (ВСТП), приведем оценочные позиции России в экономическом, социальном и культурном пространстве (табл. 1), которые косвенно, но вполне убедительно характеризуют степень привлекательности страны у зарубежных туристов и соответственно формируют знак и степень восприятия образа российских туристов за рубежом.

Таблица 1. Места России в авторитетных рейтингах стран мира

\begin{tabular}{|c|c|c|}
\hline Название рейтинга или индекса & Год & $\begin{array}{c}\text { Место России / } \\
\text { Общее количество стран }\end{array}$ \\
\hline Рейтинг стран по ВВП на душу населения & 2018 & $67 / 194$ \\
\hline Индекс глобальной конкурентоспособности & 2018 & $43 / 140$ \\
\hline Рейтинг стран по уровню образования & 2018 & $32 / 189$ \\
\hline Рейтинг стран по уровню социального развития & 2018 & $60 / 146$ \\
\hline Рейтинг верховенства закона & 2018 & $89 / 113$ \\
\hline Уровень экологической эффективности & 2018 & $52 / 180$ \\
\hline Рейтинг стран по уровню терроризма & 2017 & $33 / 134$ \\
\hline Индекс развития человеческого потенциала & 2018 & $49 / 189$ \\
\hline $\begin{array}{l}\text { Рейтинг по уровню развития информационно-коммуникационных } \\
\text { технологий }\end{array}$ & 2017 & $45 / 176$ \\
\hline Рейтинг по уровню процветания стран & 2018 & $96 / 149$ \\
\hline Индекс качества жизни пожилых людей & 2017 & $65 / 96$ \\
\hline Глобальный пенсионный индекс & 2017 & $40 / 43$ \\
\hline Глобальный индекс миролюбия & 2018 & $154 / 163$ \\
\hline Всемирный индекс счастья & 2016 & $116 / 140$ \\
\hline Рейтинг стран по уровню свободы Интернета в мире & 2016 & $52 / 65$ \\
\hline Рейтинг репутации стран мира по версии Reputation Institute & 2013 & $46 / 50$ \\
\hline Индекс конкурентоспособности путешествий и туризма & 2015 & $126 / 146$ \\
\hline Рейтинг привлекательности страны у зарубежных туристов & 2015 & $45 / 134$ \\
\hline Рейтинг по продвижению туризма на зарубежных рынках & 2017 & $80 / 148$ \\
\hline
\end{tabular}

Источник: Систематизировано автором по данным: Центр гуманитарных технологий, 2006-2019 (последняя редакция: 30.03.2019).- URL: http://gtmarket.ru/ratings 
Как видно из данных таблицы 1 , рейтинговые позиции России пока не соответствуют статусу «ведущей мировой державы XXI века, с привлекательным образом жизни, занимающей передовые позиции в глобальной экономической конкуренции...», который был провозглашен «Концепцией долгосрочного социально-экономического развития Российской Федерации на период до 2020 года» [2].

Напомним, что в этом основополагающем документе, утвержденном Правительством РФ еще в ноябре 2008 года, были обозначены следующие целевые ориентиры.

1. Занять место в пятерке стран, которые лидируют по среднедушевому показателю ВВП.

2. Достигнуть благосостояния, сопоставимого с уровнем самых развитых стран.

3. Создать необходимые условия для развития интеллектуального капитала (потенциала).

4. Войти в число мировых технологических лидеров.

5. Поднять среднюю ожидаемую продолжительность жизни - примерно до 72-75 лет.

6. Довести долю среднего класса до 0,6-0,7 от общей численности населения.

7. В основном завершить догоняющее развитие России, т.е. осуществить переход от энергосырьевой и инерционной к инновационной модели развития экономики.

8. Избежать новой гонки вооружений и «холодной войны».

K сожалению, реальность не оправдывает эти надежды. В настоящее время по среднедушевому доходу Россия занимает не пятое, a - 67 место из 197 стран, зафиксированных в списке. По индексу глобальной конкурентоспособности, хотя и сделаны некоторые позитивные шаги,43 место. Слабо продвинулась страна и по другим показателям: по уровню образования - 32 место; по индексу социального прогресса -60 место; по рейтингу верховенства закона -89 место; по уровню экологической эффективности - 52 место; по уровню терроризма - 33 место.

При удовлетворительном индексе человеческого потенциала (49 место из 189) и уровне развития информационно-коммуникационных технологий (45/176) страна по уровню процветания находится ближе к концу «турнирной таблицы» (96 место из 149). Особо удручает рейтинг качества жизни пожилых россиян («Global Age Watch Index) - 65 место из 96 и «глобальный пенсионный индекс (Global Retirement Index)», в котором Россия находится в пятерке худших стран - 40-е место из 43 возможных, причем еще до реформы ее пенсионной системы в 2018 году. Напрягает позиция страны в рейтинге миролюбивых стран - 154-место из 163.

Незавидно положение России в так называемом «индексе счастья», который не отражает социально-экономические достижения, но дает общее представление о «степени удовлетворённости жителей каждой страны». По этому показателю Россия занимает 116 место из 140 возможных мест. Трудно ожидать, что такая самооценка удовлетворенности жизнью россиян вкупе с пугающим рейтингом агрессивности страны может служить дополнительным стимулом ее посещения зарубежными туристами и восприятия положительного образа «русо туриста» в зарубежных турах. В этом отношении показательна информация, представленная на туристическом Интернет-портале TripAdvisor. Здесь на протяжении многих лет «маячит» рейтинг, в котором Москва стоит на третьем месте среди самых недружелюбных местных жителей и самых дорогих городов мира [3]. К этому можно добавить популярный среди туристов сайт WorldAtlas, где Ростов-на-Дону находится на первой строчке рейтинга самых криминальных населенных пунктов Европы. Потому вряд ли стоит удивляться тому, что при высоких рейтинговых оценках природных богатств нашей страны (5-е место) и объектов ее культурного наследия (9-е место) Россия находится на 126 месте из 146 возможных в «индексе конкурентоспособности путешествий и туризма» и на 45 месте в рейтинге привлекательности страны у зарубежных туристов.

Естественно, такое положение дел в национальной индустрии туризма не может устраивать руководство страны. Но оно продолжает односторонний путь к решению этой проблемы: вкладывает основные ресурсы в туристскую инфраструктуру, оставляя крохи на создание благоприятного международного имиджа. Об этом красноречиво говорит тот факт, что Россия пока не имеет туристических представительств, действующих за рубежом, в то время как на своей территории находится более 40 зарубежных представительств. Результат такой информационно-аналитической и коммуникационной политики в значительной мере отражает рейтинг ВСТП по продвижению туризма на зарубежных 
рынках - 80 место.

Достоверность приведенных выше рейтинговых оценок подтверждает сравнение динамики выездных и въездных туристских поездок в 2014-2017 гг. (табл. 2), из которого следует почти трехкратное превышение выездного (импорт) над въездным (экспорт) туризмом, связанным с дальними странами.

Надо заметить, что выше представленная динамика туристских потоков не отражает целевую дифференциацию и финансовые результаты, позволяющие составить более полную картину тенденций развития национальной индустрии туризма. Так, при сокращении въездного физического потока на 17,8\% в 2016 году, падение финансовых поступлений в долларах составило более $25 \%$ в сравнении с 2014 годом. Аналогично, при снижении количества выездных туристов за этот период на 9,9\% долларовая выручка от зарубежных туров упала больше, чем в 2 раза [4], что привело к банкротству целый ряд туристских операторов и агентств.

Вместе с тем, даже такая статистика достаточно определенно высвечивает общую тенденцию - это снижение выездных туристских поездок и перенаправление потока российских туристов в пользу туров по России (рис. 1).

Позитивной тенденцией в настоящее время стало формирование туристскими компаниями, работающими на внутреннем рынке, «пакетных туров», включающих комплекс гостиничных, транспортных и других услуг в межрегиональном масштабе [5]. Также можно выделить несколько «точек роста» современного качественного внутреннего туризма (например, сочинский курорт «Роза Хутор»), рассчитанного на средний ценовой сегмент, что позволило после Олимпийских игр 2014 нивелировать фактор сезонности, в частности поднять средний коэффициент заполнения гостиниц с 0,25 до 0,45.

Тем не менее, 2017-2018 годы для внутреннего туризма считаются годами «упущенных возможностей». Предоставленный новыми геополитическими обстоятельствами уникальный шанс для устойчивого развития внутреннего туризма не был в полной мере использован по целому ряду причин объективного и субъективного плана.

Одной из главных причин, по нашему мнению, является недостаток маркетингового и

Таблица 2. Динамика выездных и въездных туристских потоков, млн. чел. (2014-2017 гг.)

\begin{tabular}{|l|c|c|c|c|}
\hline \multirow{2}{*}{} & \multicolumn{3}{|c|}{ Год } \\
\cline { 2 - 5 } & 2014 & 2015 & 2016 & 2017 \\
\hline В страны дальнего зарубежья & 22,12 & 20,92 & 19,94 & $28,60^{*}$ \\
\hline Всего & 42,92 & 34,39 & 31,666 & 39,63 \\
\hline Из стран дальнего зарубежья & 9,1 & 8,36 & 7,86 & 8,13 \\
\hline Всего & 29,85 & 26,85 & 24,57 & 24,4 \\
\hline
\end{tabular}

* Эта цифра включает в себя неоднократные перемещения граждан Абхазии с российскими паспортами Источник: Составлено автором на основе данных Росстата и ФСБ РФ
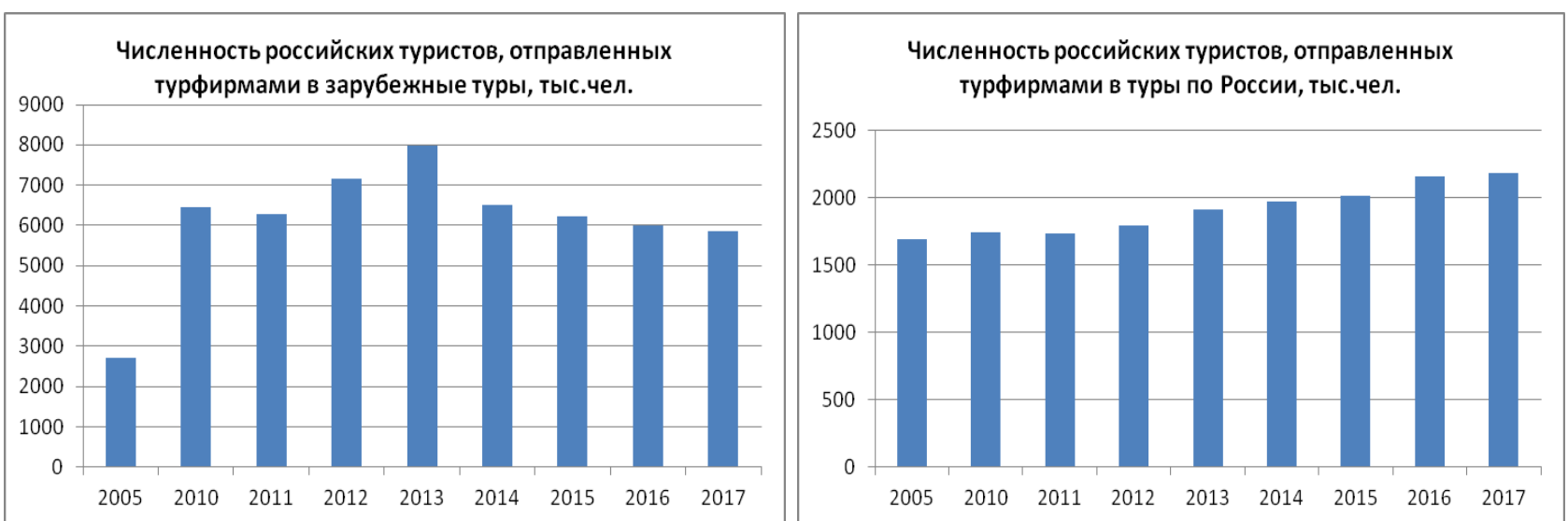

Puc. 1. Динамика зарубежных туров и туров по России, организованных турфирмами для граждан России Источник: Обработано автором по данным Росстата (см.: Россия в цифрах. 2018: Крат. стат. сб. - М.: Росстат, 2018. - 522 с.) 
стратегического мышления у лиц, принимающих решения (ЛПР) в туристской отрасли. В конкретной форме это проявляется в завышенных ценах на туристские услуги невысокого качества, что приводит к росту самостоятельного туризма, который в пределе ограничивается дачным участком или просто выездом за город.

При этом можно понять руководство туристской отрасли, которое в последние годы (для иностранных туристов с 2013 г., а российских - с 2015 г.) четко видит появление «стратегических разрывов» в Федеральной целевой программе по развитию туризма в 2011-2018 годы [6], и делает все возможное для их устранения любой ценой (табл. 3).

Как видно из данных таблицы 3, в 2018 году планировалось увеличить численность размещенных в гостиницах иностранных граждан на 539\%, а российских в 10 раз меньше. Однако реальное количество иностранных туристов оказалось почти в 4 раза ниже, а российских, напротив - в 1,5 раза выше, что свидетельствует о неадекватности принятой стратегии активного развития въездного и стратегия пассивного развития внутреннего туризма.

Несмотря на то, что в 2017-18 гг. въездной туризм несколько подрос (в целом на 1,8\%), логика санкционного давления западных стран на Россию не дает особых надежд на существенный рост финансовых показателей экспортного туризма, в частности за счет облегчения визового режима и других преференций для жителей Китая. Этот ход мы считаем имитацией борьбы за иностранного туриста, которая имеет мало общего со стратегически выверенными действиями, направленными на полноценное развитие национальной индустрии туризма.

Между тем, маркетинговый анализ динамики окружающей среды и поведения потре- бителей на рынке внутреннего туризма, показывает, что культивируемая в последние годы идеология патриотизма слабо связана с итогами развития рынка внутреннего туризма, объективно создающего ощущение любви к родине, уважение к культурам и обычаям, населяющим ее народностям. Основное противоречие, по нашему мнению, состоит в следующем. С одной стороны, низкий среднестатистический уровень доходов у основной части населения страны не способствует ускоренному развитию указанного сегмента рынка, поскольку денег на организованный отдых и проезд к нему практически не остается. С другой стороны, та сравнительно немногочисленная часть населения, которая располагает средними и высокими по европейским меркам доходами, имеет схожие с западными туристами предпочтения. Здесь нужно выделить весьма важный момент, который проявляется в процессе сравнения доходов российского среднего класса с доходами среднего класса экономически развитых стран. По этому критерию в настоящее время только 19-20\% населения следует относить - к среднему классу.

Не меньшей проблемой национального туризма считается крайняя неравномерность экономического развития регионов: доходы самого богатого региона примерно в 25 раз выше, чем самого бедного.

Для раскрытия сущности этого вопроса коснемся истории его возникновения. Как известно, в 90-е годы ХХ века резко возросло число бедных среди россиян и одновременно возник слой богатых «новых русских». В нулевые годы XXI века высокие нефтяные котировки позволили российским властям существенно снизить долю бедного населения. Но затем, в мае 2015 года, реальные доходы снова упали, составив 86\% от зарплат за этот же месяц 2014 года. Скорость их

Таблица 3. Сравнение целевых и реальных показателей численности российских и иностранных туристов в коллективных средствах размещения (КСР) по годам

\begin{tabular}{|l|c|c|c|c|c|c|c|c|c|}
\hline \multicolumn{1}{|c|}{ Показатели } & 2011 & 2012 & 2013 & 2014 & 2015 & 2016 & 2017 & 2018 & $\begin{array}{c}\text { Прирост в } \\
\text { \% к 2010 г. }\end{array}$ \\
\hline $\begin{array}{l}\text { Численность граждан РФ, } \\
\text { размещенных в КСР, млн. } \\
\text { чел. }\end{array}$ & $\underline{31,5}$ & $\frac{31,9}{31,8}$ & $\frac{32,5}{32,6}$ & $\frac{33,4}{33,8}$ & $\frac{34,8}{43,7}$ & $\frac{37,1}{48,2}$ & $\frac{40}{56,5}$ & $\frac{45}{59,7}$ & 54,6 \\
\hline $\begin{array}{l}\text { Численность иностранных } \\
\text { граждан, размещенных в } \\
\text { КСР, млн.чел. }\end{array}$ & $\underline{4,1}$ & $\frac{4,6}{4,2}$ & $\frac{5,4}{4,4}$ & $\frac{6,6}{4,6}$ & $\frac{8,7}{5,6}$ & $\frac{11,9}{6,1}$ & $\frac{16}{5,8}$ & $\underline{\underline{23}}$ & 538,3 \\
\hline
\end{tabular}

Примечание: в числителе приведены целевые, а в знаменателе - реальные показатели

Источник: Составлено автором на основе данных ФЦП «Развитие внутреннего и въездного туризма в Российской Федерации» (2011-2018 годы)» и Росстата 
снижения удалось понизить только в 2017 году. При этом, как отмечается в ежегодном докладе ТПП РФ, официальные цифры занижены: бедных не менее 22\%. Да и эта цифра полностью не отражает печальную структуру российской бедности (рис. 2), которая получила название «сверхновая бедность», что означает бедность при наличии стабильной легальной работы [7].

Исходя из этих сведений и фактов, рассмотрим две разные точки зрения авторитетных аналитиков на среднесрочный прогноз развития ситуации в туристском бизнесе страны. Одни считают, что разумнее всего придерживаться стратегии выжидания, рассчитывая на вариант, когда маятник развития событий вернется в состояние 2013-2014 гг. Этот вариант прогноза считается оптимистическим и на его существование в принципе можно рассчитывать. В целом их рекомендации сводятся к дальнейшему росту инвестиций в туристскую инфраструктуру для привлечения в страну иностранных туристов, что, как предполагается, будет способствовать росту ВВП, повышению числа рабочих мест и улучшению состояния экономики страны.

Другие аналитики (например, эксперты из Института экономической политики им. Е.Т.Гайдара и Всероссийской академии внешней торговли) не видят оснований для такого оптимизма. Они полагают, что наблюдаемые в 2017-2018 гг. восстановительные тренды не долгосрочны, и не обеспечат выхода на необходимую динамику роста национальной индустрии туризма в среднесрочном периоде, особенно с учетом постоянного усиления санкций со стороны США и существующего уровня цен на нефть
[10].

В целом мы больше склонны принять вторую точку зрения как более вероятную. Полагаем, что проявившаяся тенденция роста спроса на услуги внутреннего туризма и снижения спроса на зарубежный туризм имеет не столько циклический, сколько системный характер, к которому придется приспосабливаться в среднесрочной перспективе. Некоторое снижение темпов роста спроса на внутренний туристский продукт и незначительный рост спроса на зарубежные туры в 2017-2018 годах следует рассматривать как временное явление, обусловленное низкой адаптивностью отрасли к переменам спроса на ее услуги. Уместно напомнить, что вся история советского туризма была связана прежде всего с удовлетворением потребностей человека в путешествиях внутри страны. И только с 90-х годов XX века, когда страна взяла курс на рыночный путь развития и открытость границ, последовал всплеск выездного туризма, который постепенно показал и обратную сторону. Основная часть «старой» туристской индустрии, преимущественно нацеленной на некачественный, но весыма доступный массовый внутренний туризм, сошла с дистанции. Другая, значительно меньшая часть, пережив сильный шок, достаточно успешно адаптировалась к новым условиям, сделав ставку в основном на выездной туризм в страны, где были созданы туристские дестинации, обеспечивающие высокий конкурентный показатель по шкале «цена-качество». По факту, современные российские туроператоры и турагентства стали филиалами транснациональных туристских компаний, перекачивающими ва-

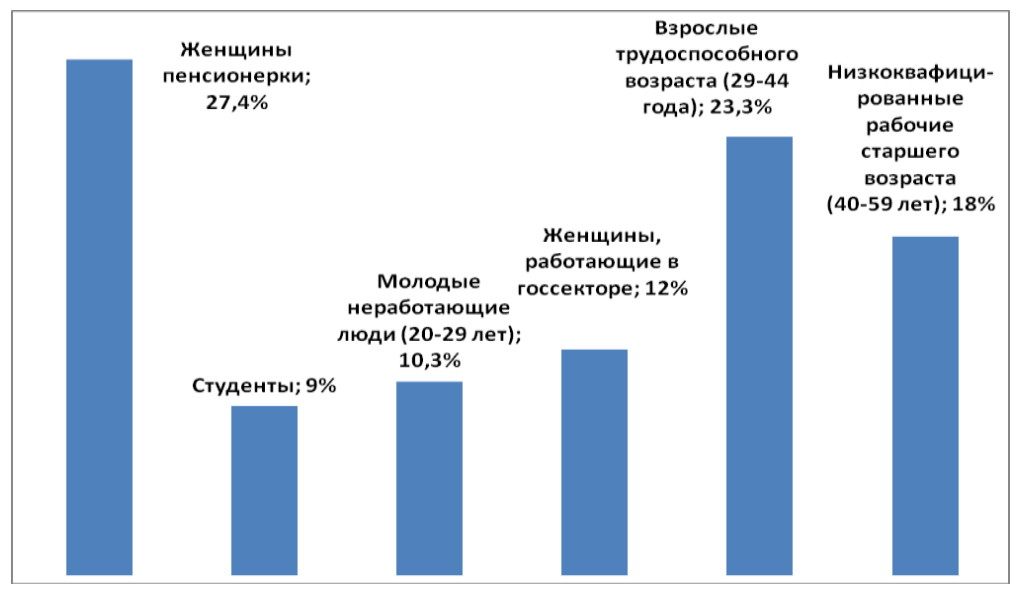

Puc. 2. Структура российской бедности (состав $40 \%$ населения с наиболее низкими доходами) Источник: Составлено автором на основе данных ФЦП «Развитие внутреннего и въездного туризма в Российской Федерации» (2011-2018 годы)» и Росстата 
люту россиян в пользу их развития (по некоторым данным в среднем в год за рубеж «утекает» порядка 50 млрд. долл.). Потому неудивительно, что, начиная с 2000-х годов, выездной туризм постоянно демонстрировал высокие темпы роста, достигнув пика в 2013-2014 гг. Тогда россиянами было совершено около 17,6 млн. зарубежных туров. Эта цифра может нас впечатлять, если не считать, что по официальным данным всего чуть больше 20\% граждан России за указанный период выезжали за ее пределы. Среди них 12\% фактически совершали не туристские, а деловые поездки [11]. Достоверность этой статистики подтверждают данные ФМС, согласно которым две трети россиян до сих пор не имеют загранпаспортов [12]. Именно из них формируется основной «контингент» внутреннего туризма, которым по самым скромным подсчетам охвачено 35-40\% населения РФ [13], что трехкратно превышает лучшие показатели выездного туризма. Заметим, что этот показатель не является высоким в сравнении с европейскими странами, где внутренний турпоток охватывает более 50\% населения, а в США и того больше - 80\% [8].

Следовательно, в нестабильных условиях функционирования национальной индустрии туризма не существует разумной альтернативы ее позитивного развития без борьбы за внутреннего туриста путем формирования, стимулирования и удовлетворения спроса на экономически доступные и достаточно качественные туристские услуги. В этом плане мы полностью солидарны с мнением Л.П. Кульгачева и М.М. Романовой, которые правомерно считают, что «Россия способна значительно увеличить посещение отечественных туристских дестинаций своими гражданами» [9, с.810]. Без решения этой задачи получить необходимую для разви- тия отрасли устойчивую прибыль чрезвычайно сложно. Как показывает многолетняя практика, въездной (экспортоориентированный) туризм за исключением краткого периода проводимых в стране событийных мероприятий мирового и европейского масштаба, имеет ограниченную целевую аудиторию, которая, как правило, не покрывает в должной мере понесенные на создание современной туристской инфраструктуры и обслуживание зарубежных клиентов, затраты. Попытки увеличить количество приезжающих в Россию туристов из Китая и других «целевых стран» путем частичной компенсации понесенных ими затрат [14] допустимы, если эта компенсация не ляжет на плечи малообеспеченных соотечественников.

Справедливости ради, необходимо обратить внимание на новый Федеральный закон, направленный на активизацию организованного внутреннего туризма, согласно которому с января 2019 года работодатель может официально оплачивать отдых сотруднику, а также членам его семьи в размере 50 тысяч рублей [15]. Однако данный закон, скорее всего, станет «работать» в экономически успешных корпорациях, где, как правило, ценные сотрудники принадлежат к хорошо обеспеченным слоям населения. Вместе с так называемыми «невыездными» они рассматривает внутренний туризм преимущественно как временный выход из создавшейся обстановки. Поэтому маловероятно, что вклад этого закона в развитие конкурентоспособного внутреннего туризма станет существенным, пока не будет успешно решена проблема снижения уровня бедности и роста среднего класса, предпочитающего организованный отдых в пределах своей страны.

\section{Библиографический список}

1. Сагидуллаева, М.С. Социально-экономическая сущность, особенности и задачи туристского маркетинга// М.С. Сагидуллаева// РИСК: Ресурсы, информация, снабжение, конкуренция.- 2018.- № 4 (октябрь-декабрь).-с.18-22.

2. Концепция долгосрочного социально-экономического развития Российской Федерации на период до 2020 года. Утв. распоряжением Правительства РФ от 17 ноября 2008 г. № 1662-р, МЭРТ, 2008.

3. Логунцова, И.В. Маркетинговый подход к системе управления современным городом // Государственное управление.- Электронный вестник. - Выпуск № 15.- Июнь 2008 г. - URL: https://www.yandex.ru/search/?1 $\mathrm{r}=39$ \&clid=2175661\&text.

4. Восстановление спроса на туристские услуги в России. Выпуск № 31, ноябрь 2017.- М.: Аналитический центр при Правительстве РФ, 2017.- с. 7, 13.

5. Глаголев А.Б. Внутренний туризм в России 2013-2017 гг.- упущенные возможности.- URL: http://sciarticle.ru/stat.php?i=1516001488. 
6. Федеральная целевая программа «Развитие внутреннего и въездного туризма в Российской Федерации» (2011-2018 годы)». Утв. пост. Правительства РФ от 2 августа 2011 г. № 644.

7. Ежегодный доклад. «Потребительский рынок России: итоги 2016 года, перспективы на 2017 год» - М., Комитет ТПП РФ по развитию потребительского рынка, апрель, 2017 г. - 82 с.

8. Быстров, С.А. Внутренний туризм как стратегически важное направления развитие туристского рынка РФ [Текст] / С.А. Быстров // Научно-методический электронный журнал «Концепт»._- 2016. - Т. 15.-c.966-970.

9. Кульгачёв, И. П. Предложения по развитию внутреннего туризма в Российской Федерации [Текст] / И.П. Кульгачёв, М.М. Романова /Молодой ученый (Международный научный журнал). - № 11 (115). - 2016._ с. 804811.

10. URL: http://argumentiru.com/economics/2017/08/468597?utm_campaign=redtram\&utm_content=268806038 \&utm_source $=361403$

11. URL: http://okoplanet.su/politik/politiklist/304261vnutrenniyturizmporarazrushatstereotipy.html

12. Петров В. Две трети россиян не имеют загранпаспортов // Российская газета 09.04.2014

13. Совещание о развитии внутреннего туризма// Правительство РФ 2016.- URL: http://government.ru/ news $/ 21363$

14. Премьер-министр России Дмитрий Медведев поручил проработать вопрос о возможности компенсации части стоимости туристических путевок по России для туристов из целевых стран» (cм. https:// iz.ru/761145/2018-06-29).

15. URL: https://www.pnp.ru/economics/rossiyane-s-2019-goda-smogut-puteshestvovat-po-strane-za-schyotrabotodateley.html 